\title{
Nickel-Catalyzed Bromide-to-Iodide Aromatic Finkelstein Reaction
}

\section{Key words}

nickel catalysis

aryl iodides

halogen exchange
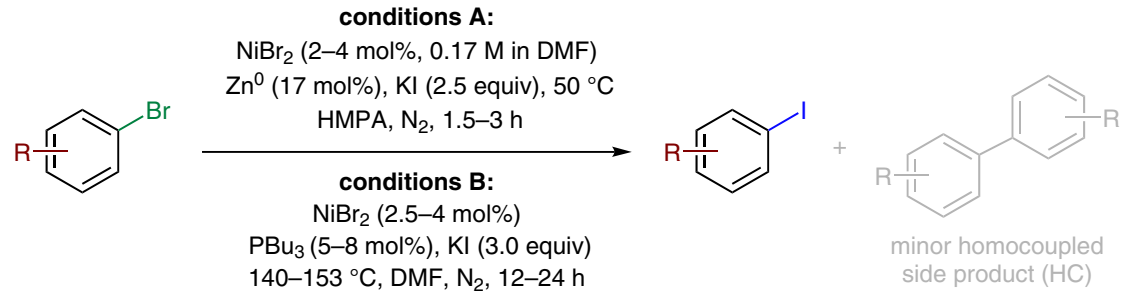

Substrate scope:<smiles>Ic1ccccc1</smiles><smiles>COc1ccc(I)cc1</smiles><smiles>CC(=O)c1ccc(I)cc1</smiles>

conditions A: $77 \%$ yield $+15 \% \mathrm{HC}$ conditions $\mathrm{A}:+\mathrm{PBu}_{3}: 74 \%$ yield $+5 \% \mathrm{HC}$ conditions B: $140{ }^{\circ} \mathrm{C}, 89 \%$ yield, no $\mathrm{HC}$

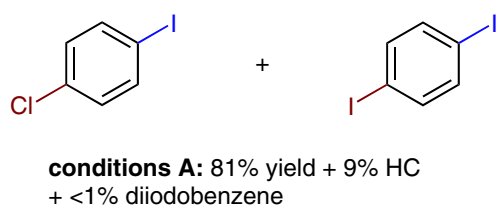<smiles>Ic1ccccn1</smiles>
$+<1 \%$ diiodobenzene

From aryl chloride:

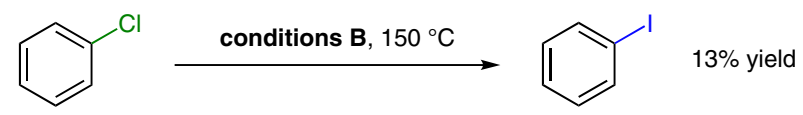

Significance: In 1978, Takagi, Hayama, and Okamoto disclosed an early example of a halogene exchange reaction using a simple nickel(II) precatalyst, with added $\mathrm{Zn}$ or $\mathrm{PBu}_{3}$, and a nucleophilic source of iodide $(\mathrm{KI})$. As the authors explain, at this time the most common strategy to perform an aromatic Finkelstein reaction was to use copper; however, the ability to go from a bromide to iodide was unattainable. This topic has remained of interest for the last 50 years, with notable contributions from a wide variety of groups.
Comment: The addition of $\mathrm{Zn}$ was crucial for the reaction to occur at lower temperatures. Moreover, it was found that the addition of a donating phosphine ligand, such as $\mathrm{PBu}_{3}$, suppressed the formation of the reductive homocoupled side product. At elevated temperatures, only the phosphine additive was necessary for a successful reaction, without the need of the $Z n$ reductant. The reaction did not occur when using various nickel(0) precatalysts. 